\title{
IMPLEMENTASI PENGGUNAAN WEB DENGAN METODE CUSTOMER RELATIONSHIP MANAGAMENT DI TENGAH PERSAINGAN ANTAR PEDAGANG KOPI
}

\author{
Afdhal Syafnur \\ Program Studi Sistem Informasi, \\ Sekolah Tinggi Manajemen dan Informatika Royal Kisaran \\ Jln.Prof.H.M.Yamin No.173 Telp.0623 -41079, Kisaran, Kab Asahan, Prov.Sumatera Utara-Indonesia \\ afdhal23@gmail.com
}

\begin{abstract}
Coffee is a beverage that has been popular in Indonesia, the coffee business is an interesting object to make a business opportunity. The rise of competing coffee traders now makes businesses do innovation in attracting customers and retaining customers. Customer relationship management (CRM) is a method that can be made in the promotion, service and sales process. In this information technology era, the use of web sites will be more efficient in introducing business, wide reach and easy to access anytime, anywhere. Application of the website with the customer relationship method can answer the challenges in business competition in this information technology era.
\end{abstract}

Keywords - Information Systems, Web, Coffee, Customer Relationship Management.

\begin{abstract}
Kopi merupakan minuman yang telah popular di Indonesia, bisnis kopi merupakan objek menarik untuk di jadikan sebuah peluang usaha. Maraknya persaingan pedagang kopi saat ini membuat para pelaku bisnis melakukan inovasi dalam menarik pelangga dan mempertahankan pelanggannya. Customer relationship manajement ( CRM ) merupakan sebuah metode yang dapat dijadikan landasan dalam proses promosi,pelayanan dan penjualan. Di era teknologi informasi ini, penggunaan website akan lebih efisien dalam melakukan sebuah pengenalan bisnis, jangkuan luas dan mudah di aksesk kapanpun dan dimanapun. Penerapan website dengan metode customer relationship mampu menjawab tantangan dalam persaingan bisnis di era teknologi informasi ini.
\end{abstract}

Kata kunci-Sistem Informasi, Web, Customer Relationship Management, Kopi.

\section{PENDAHULUAN}

Meningkatnya para pedang kopi saat ini tidak terlepas dari gaya hidup. Minuman kopi merupakan minuman yang popular di masyarakat Indonesia karena rasa dan aromanya mempunyai ciri khas. Hal ini juga sama dengan yang ada diluar negeri dimana pada umumnya masyarakat menyukai minum kopi.

Usaha kedai kopi pada saat ini tumbuh dengan pesat. Hal ini dapat dilihat munculnya kedai kopi dengan beraneka ragam merek salah satu waroeng kopi kasiko.Persaingan pasar menjadi salah satu pekerjaan rumah bagi para pelaku usaha ini. Berbagai macam tantangan karna banyak para pedagang kopi melebarkan usahanya.

Sistem Informasi saat ini sudah sangat berkembang,salah satunya dalam penggunaan website sebagi sarana usaha untuk meningkatkan pelayanan sebagai strategi untuk menjangkau pelanggan yang lebih banyak lagi.

Customer Relationship Manajement adalah sebuah cara yang dipakai guna mengetahui secara mendalam keperluan dan tingkah laku pelanggan pada saat memperluas jaringan pelanggan. Dengan kata lain CRM bisa di artikan sebagai fungsi yang dapat melayani serta mempromosikan objek yang akan di kembangkan untuk mendapatkan keuntungan yang lebih besar. Hal ini tentu akan berkembangnya akses dengan cepat dari bidang pemesanan serta pelayanan pada konsumen.

Website merupakan sarana yang banyak digunakan oleh perusahan maupun pribadi untuk menjangkau dan memberikan pelayanan kepada pelanggan . Dengan ini penerapan metode Customer Relationship sangat dibutuhkan dalam membangun sebuah website untuk meningkatkan mutu pelayanan kepada pelanggan.

\section{A. CRM}

menurut Buttle (2007:48) yaitu“ CRM adalah strategi inti dalam bisnis yang mengintegrasikan proses-proses dan fungsi-fungsi internal dengan semua jaringan eksternal untuk menciptakan serta mewujudkan nilai bagi para konsumen sasaran secara profitabel"[1].

Sedangkan menurut Temporal dan Troot (2002:7) berpendapat bahwa "CRM pada intinya merupakan kolaborasi dengan setiap konsumen yang mampu menciptakan keadaan yang tidak merugikan salah satu pihak (win-win situation)[1]. 
Menurut Utami (2010:179)pengertian CRM adalah "Suatu proses interaktif yang mengubah datadata pelanggan kedalam kesetiaan pelanggan melalui beberapa kegiatan, yaitu mengumpulkan data pelanggan, menganalisis data pelanggan tersebut dan mengidentifikasi target pelanggan, mengembangkan program CRM, dan menerapkan program CRM"[1].

Berdasarkan dari beberapa pendapat yang telah dikutip bahwa customer relationship merupakan sebuah cara yang digunakan untuk menjalin kerja sama yang baik dengan pelanggan lama serta membuka kesempatan bisnis baru bagi pelanggan yang baru.

\section{B. Tahap - tahap Customer Relationship}

Adapun tahapan - tahapan dalam CRM adalah sebagai berikut:

1. Mendapatkan pelanggan baru.

Hal ini dapat dilakuan dengan memberikan akses yang mudah dalam mendapatkan informasi secara cepat.

2. Peningkatan Hubungan dengn Pelanggan. Cara ini dapat dilakukan dengan memberikan pelayanan yang baik seprti memberikan hadiah kepada mitra dan pelanggan tetap.

3. Mempertahankan pelanggan.

Dalam hal ini dapat di ambil langkah memenuhi harapan pelanggan.

\section{Manfaat CRM}

CRM dibuat dengan tujuan dimana pada akhirnya adalah untuk pencapaian bisnis yaitu keuntungan.Adapun tujuan customer relationship sebagai berikut :

a. Menjalin hubungan yang baik dengan pelanggan guna meningkatan keuntungan pada usaha yang dijalankan

b. Menyediakan informasi yang lenkap mengenai jenis usaha yang di jalani.

c. Efisiensi waktu dalam penyebaran informasi kepada pelanggan melalui pemanfaatan teknologi informasi.

\section{METODE PENELITIAN}

Dalam melakukan penelitian ini, berdasarkan teori - teori serta permasalahan yang ada pada kedai kopi kasiko maka penulis menggunakan metode kualitatif dengan langkah sebagai berikut.

Dalam pengumpulan data dan informasi untuk penulisan ini, penulis melakukan beberapa cara yaitu :

1. Tinjauan Lapangan
Pada tahap ini, penulis langsung data ke lokasi objek penelitian, guna mendapatkan data secara langsung.

2. Wawancara

Tahap ini, proses wawancara langsung dengan pemilik waroeng kopi.

3. Tinjauan Pustaka

Mempelajari literature yang berhungan dengan permasalahan yang sedang di teliti.

4. Proses Data

Perolehan data dari hasil pengamatan langsung ke lokasi dan wawancara dengan pemilik,data di kelompokkan sesuai dengan kebutuhan.

5. Peracangan Website

Tahap ini dimulai dari perancangan interface, perancangan input dan database sesuai dengan kebutuhan.

6. Implementasi Sistem

Tahapan ini adalah penggunaan system yang telah di bangun.

\section{HASIL DAN PEMBAHASAN}

\section{Diagram Use Case}

Diagram Use Case adalah scenario system yang akan dibangun. Pada system ini terdapat 2 aktor yaitu admin dan pelanggan.

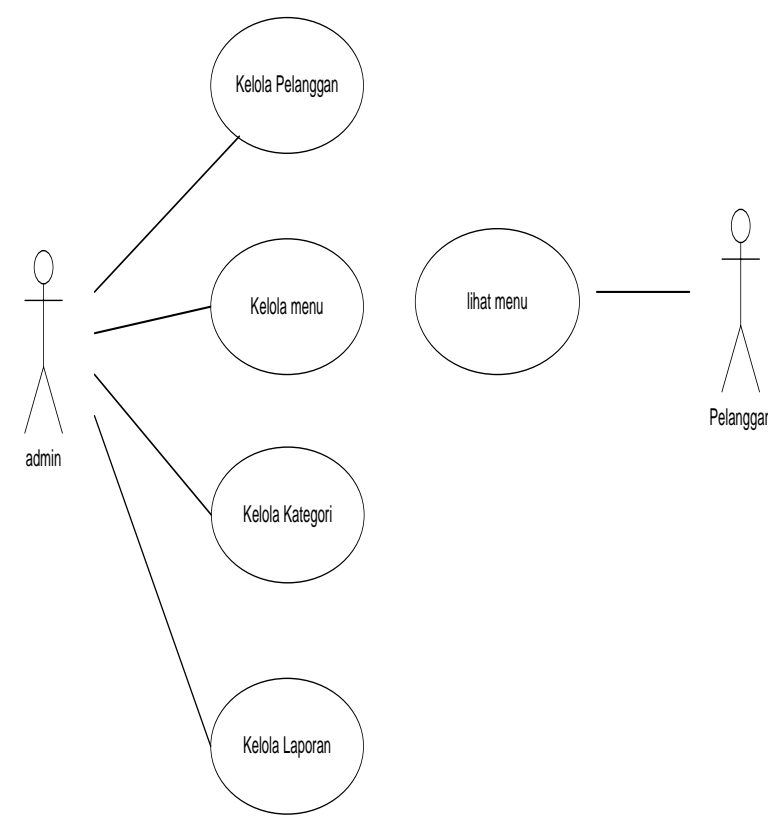

Gambar 1. Diagram Use Case 


\section{Diagram activity Pelanggan}

Dalam penggunaan sistem ini, pelanggan dapat melakukan aktifitas seperti pada gambaran aktifity dibawah ini.

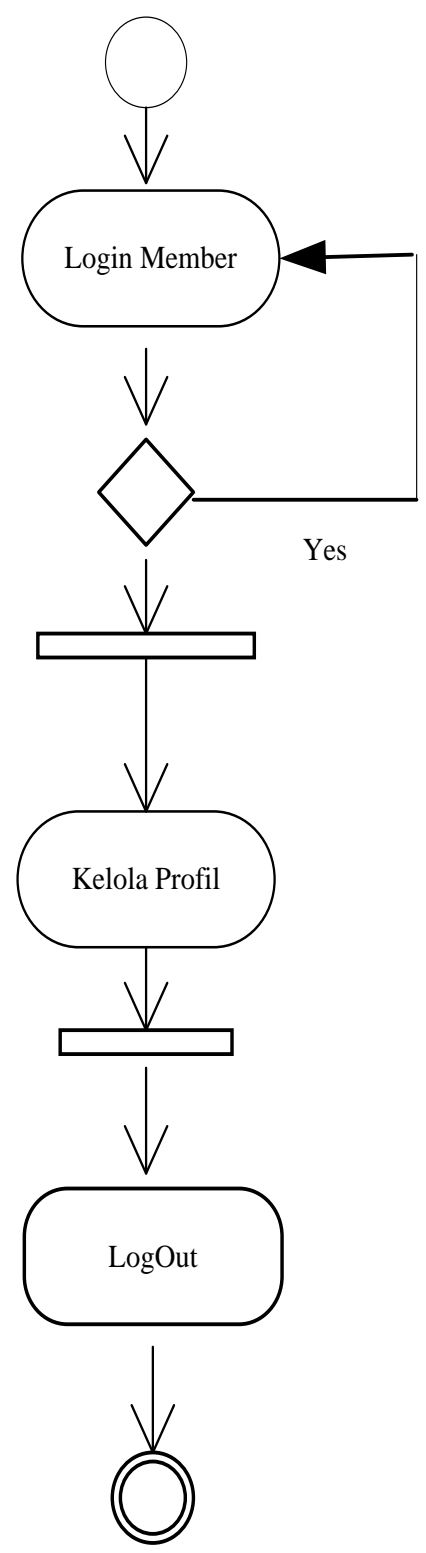

Gambar 2. Diagram activity Pelanggan
3. Activity diagram admin

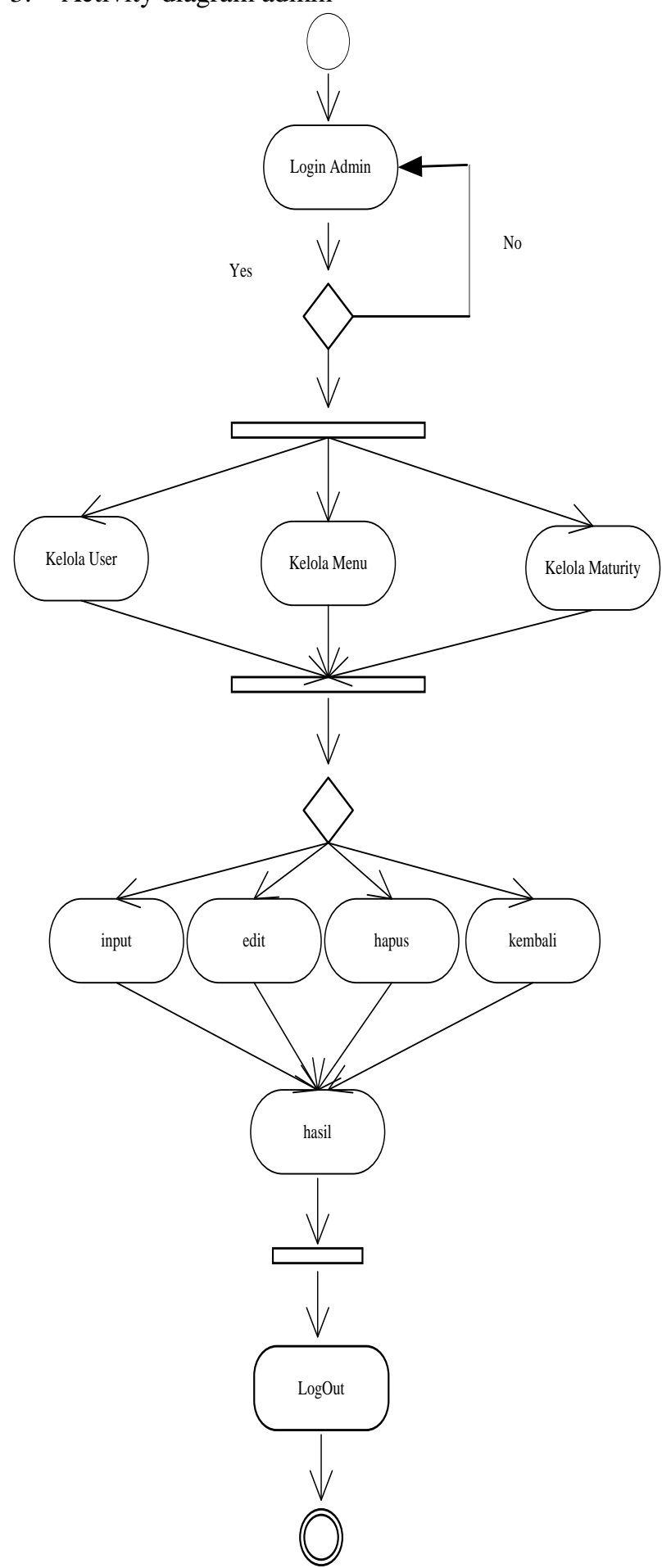

Gambar 3. Diagram activity Admin 
Gambar 3 menunjukkan aktifitas yang dilakukan oleh admin pada system ini.

\section{Diagram Sequence}

Diagram sequence adalah bentuk komunikasi antar objek dan memberikan petunjuk atau tanda komunikasi antar objek.

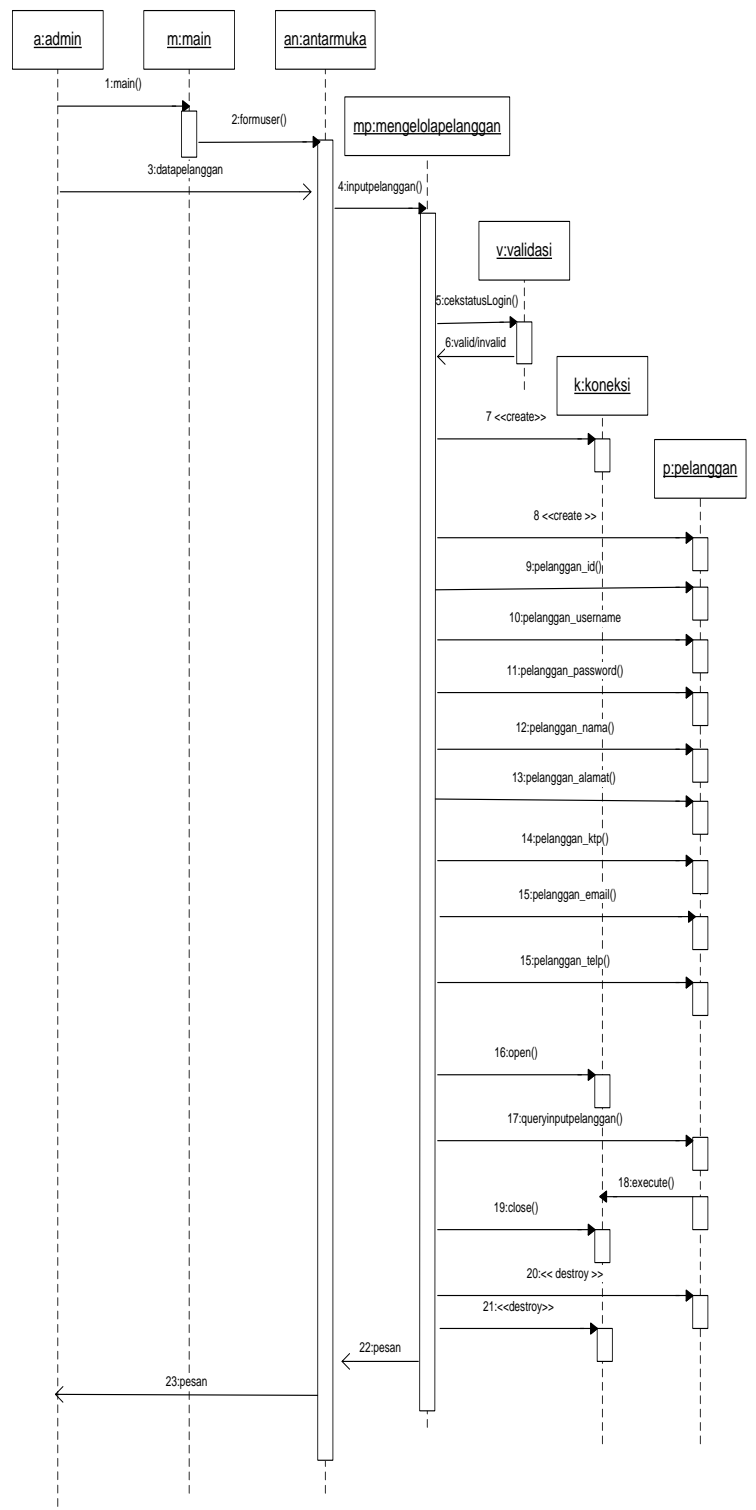

Gambar 4. Diagram Sequnce Pelanggan

Gambar di atas menjelaskan bagaimana proses penambahan pelanggan pada system yang di bangun

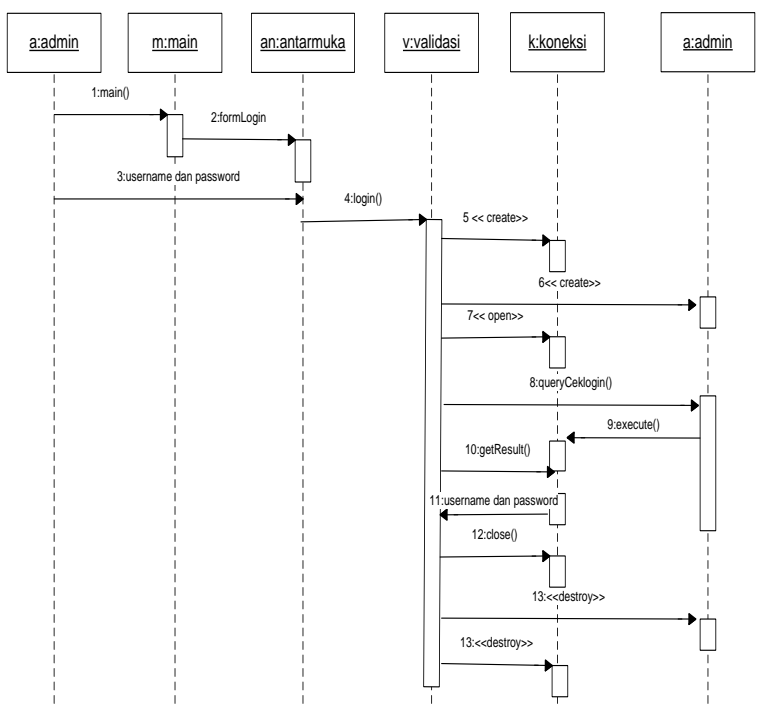

Gambar 5. Sequence Diagram Login Admin

Dari gambar 10 terlihat alisan pesan akses sistem yang dilakukan oleh admin.

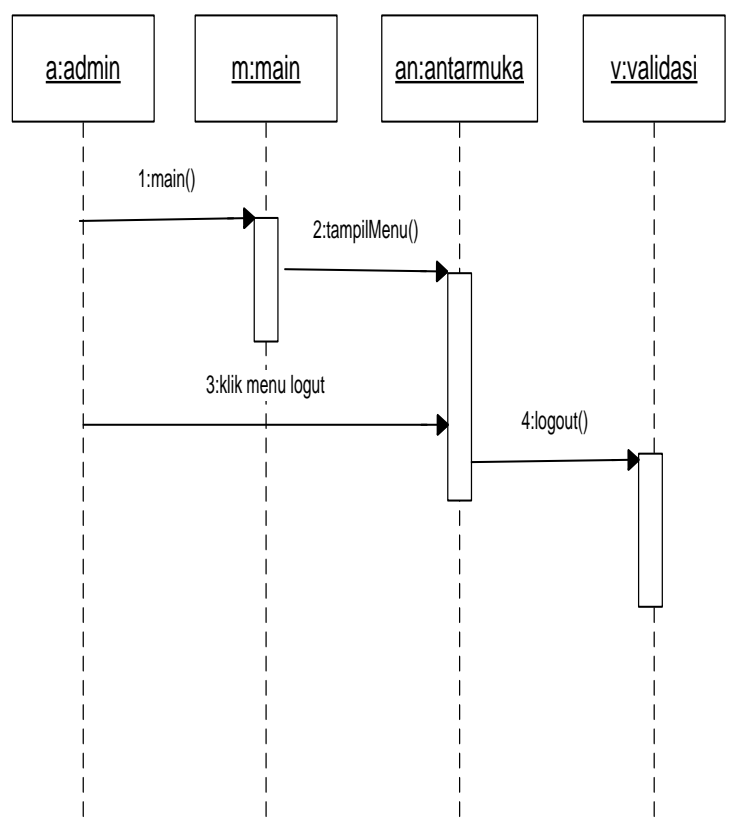

Gambar 6. Sequence Diagram Logout Sistem 

A. Implementasi
Web Customer
Relationship Management
1. Login Sistem

3. Data admin

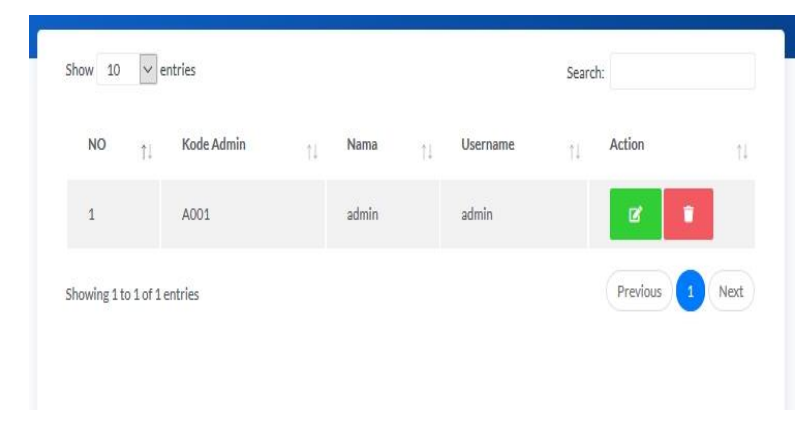

\section{Waroeng Kasiko}

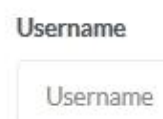

Gambar 7. Login Sistem

Pada gambar 7 adalah login system yang digunakan admin dan pelanggan untuk masuk menggunakan system.

\section{Form Admin}

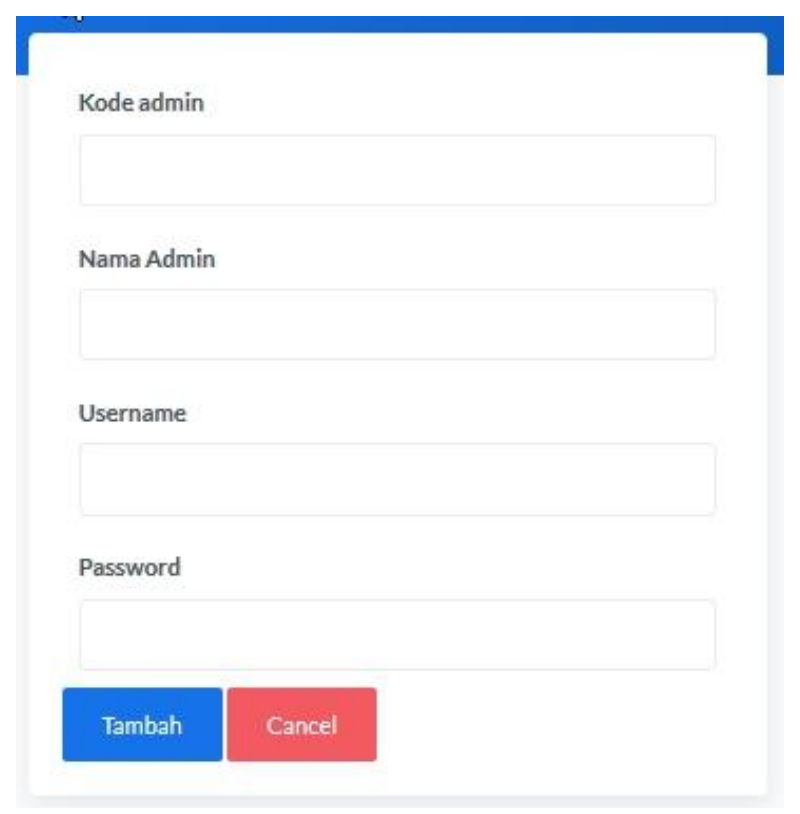

Gambar 8. Input Data admin

Pada gambar 8 implementasi proses input data admin
Gambar 9. Data admin

4. Form Pelanggan

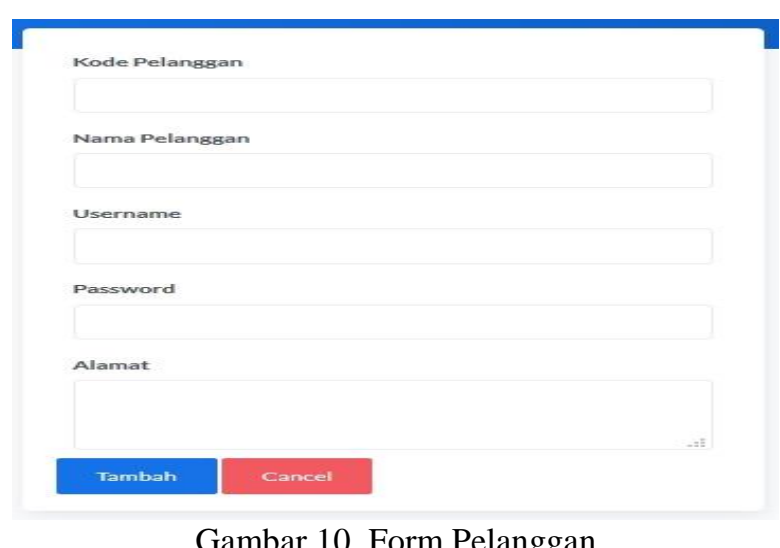

5. Data Pelanggan

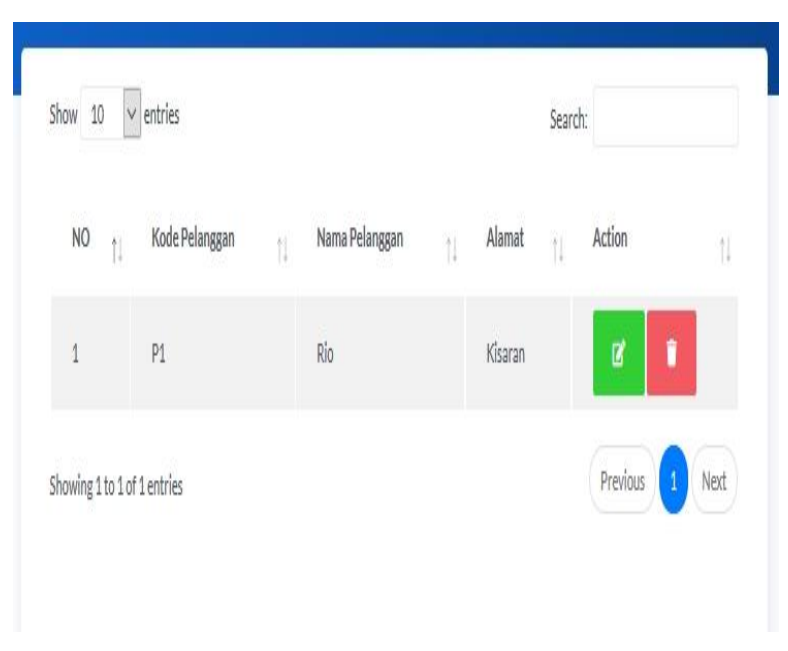

Gambar 11. Data Pelanggan 
6. Homepage

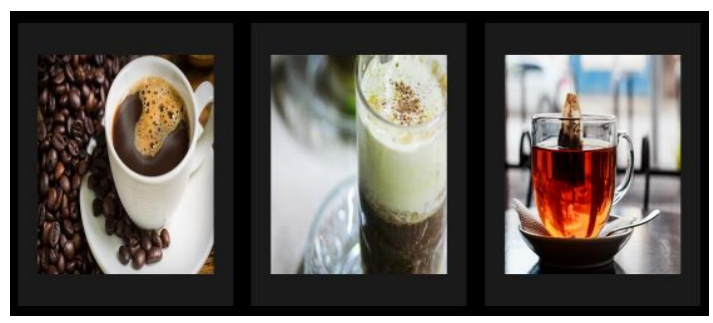

Gambar 12. Homepage

\section{KESIMPULAN}

Dari analisa yang $\mathrm{t}$ berdasarkan penulis laksnakan ,maka penulis mengambil kesimpulan sebagai berikut:

1. Menggunakan konsep dengan metode customer relationship management dapat membantu peningkatan pelayanan kepada konsumen.

2. Penerapan metode CRM dalam web dapat membantu promosi kopi dengan cepat dan efisiensi.

\section{DAFTAR PUSTAKA}

[1] A. Carissa, "PENERAPAN CUSTOMER RELATIONSHIP MANAGEMENT (CRM) SEBAGAI UPAYA UNTUK MENINGKATKAN LOYALITAS PELANGGAN (Studi Kasus pada Bandung Sport Distro Malang)," J. Adm. Bisnis, vol. 15, no. $1,2014$.

[2] I. Kholil, "Customer Relationship Management ( Crm ) Berbasis Web," J. Pilar Nusa Mandiri Cust., vol. 13, no. 1, pp. 43-48, 2017.

[3] Kusnandar, T. Penerapan Crm Dengan Sistem Informasi Berbasis Web Untuk Kepuasan Pelanggan. Jurnal Computech \& Bisnis, 5(1), 6-13. http://jurnal.stmikmi.ac.id/index.php/jcb/article/view/60. 2011

[4] Pramudiya, H. E., Dri Handarkho, Y., \& Rahayu, F. S. Dolannan Puzzle. 257-268. 2015

[5] Lumintang, M. C. L. C. Promosi Dan Customer Relationship Management Pengaruhnya Terhadap Kepuasan Nasabah Pada Pt. Bank Tabungan Negara (Persero) Cabang Manado. Jurnal Riset Ekonomi, Manajemen, Bisnis Dan Akuntansi, 1(4), 1033-1042. 2013

[6] Hamidin, D. Model Customer Relationship Management （ Crm ） DI INSTITUSI PENDIDIKAN. Seminar Nasional Aplikasi Teknologi Informasi 2008 (SNATI 2008), 2008(Snati), 31-34. 2008
[7] Oktariana, Y., Fauzi, A., \& Kumadji, S. FaktorFaktor Customer Relationship Management (Manajemen Hubungan Pelanggan) Dalam Mewujudkan Kepuasan Anggota Dan Dampaknya Terhadap Loyalitas Anggota. Jurnal Profit, 6(2), 149-162. 2012

[8] Yahya W, Y. Penerapan CRM (Customer Relationship Management) Pada Perusahaan Dagang. Penjualan Motor, 1(Bisnis Intelejen), 1-14. 2015

[9] Ningsih, N. W., Suharyono, \& Yulianto, E. Pengaruh Customer Relationship Management (Crm) Terhadap Kepuasan Dan Loyalitas Pelanggan (Survei Pada Pelanggan Pt Astra Internasional, Tbk-Tso Auto2000 Cabang Denpasar). Jurnal Administrasi Bisnis, 30(1), 171-177. 2016

[10] Mokodongan, A. Analisis Penerapan Program Customer Relationship Management Hubungannya Dengan Loyalitas Pelanggan (Studi Kasus Di Swiss Belhotel Maleosan Manado). 7, 240-271. 2010 